\title{
An evaluation of the policy of fishery resources management by TACs in European Community waters from 1983 to 1992
}

\author{
Gérard Biais
}

IFREMKR, BP 7, 17137 L'Houmem, France

Accepted April 4, 1995.

Biais G. Aquat. Living Resour., 1995, 8, 241-251.

\begin{abstract}
In 1983, the Europcan Community (EC) agreed on a system for the conservation and management of fishery resources which is based largely on the use of annual total allowable catch (TAC). Nevertheless, the state of many European stocks of demersal species has worsened since 1983. A review of TAC enforcement shows that landings have exceeded TACs to a limited extent for these resnurces. The contrary is observed for the stocks of pelagic species of which the state has improved although landings have frequently been larger than TACs. This double paradox gencrates a feeling of limited impact of the TAC system implemented by the EC. To investigate the reasons, the closeness between agreed TACs and scientific recommendations has been examined. The results show that the TAC decision process gives some preference to stability but attention is paid to the scientific recommendations. Finally, the lack of accuracy of predicted changes of hishing mortality in catch forecasis is found to have played a critical part in the failure of TACs to avoid the deteriorations of resources observed in EC waters. It leads to the conclusion that evaluation of risks in the TAC decision process and participation of actors of the fishing sector in risk management are important matters that cannot be avoided if one wants to improve the legitimacy of fishcrics management and therefore its cfficiency.
\end{abstract}

Keywords: Fishery management, quota regulations, European Community, catch predictions, Janding statistics.

Une évaluation de la politique de gestion des resserurces halieutiques par TAC dans les eaux de la Communauté Européenne de 1983 à 1992.

Résumé

En 1983, la Communauté Européenne (CE) a adopté un régime de conservation et de gestion des ressources de pêche qui est largement basé sur l'utilisation de Totaux Admissibles de Captures (TAC). Néanmoins, l'état de nombreux stocks européens d'espèces démersales a empiré depuis 1983. Un examen du respect des TAC montre que les débarquements n'ont dépassé les TAC que dans une proportion limitée pour ces ressources. Le contraire est observé pour les stocks d'espèces pélagiques dont l'état s'est amélioré bien que les débarquements aient fréquemment été plus élevés que les TAC. Ce double paradoxe génère un sentiment d'impact limité du système de TAC mis en place par la $\mathrm{CE}$. Pour en analyser les raisons, la proximité entre TAC agréés et recommandations scientifiques a été examinée. Les résultats montrent que le processus de fixation des TAC privilégie la stabilité mais prend aussi en considération les avis scientifiques. Finalement, le manque de précision des prévisions de mortalité par pêche associées aux captures recommandées est dévoilé comme ayant joué un rôle critique dans l'échec des TAC pour éviter les détériorations de la ressource constatées dans les eaux communautaires. En conséquence, l'évaluation des risques dans le processus de fixation des TAC et la participation des acteurs du secteur des péches dans la gestion des risques sont des questions importantes qui ne peuvent pas être contournées si on veut améliorer la légitimité de la gestion de pêches et par là son efficacité.

Mots-clés : Gestion dess pêches, politique des quota, Communauté Européenne, prévisions de captures, évaluation des débarquements. 


\section{INTRODUCTION}

The Common Fisheries Policy (CFP) finds bases in the Treaty of Rome (1957) which devolved power to the European Community (EC) in the sphere of Agriculture, including fisherics. However, the real birth of the CFP dates from 1970 with the adoption of the principle of equal access in EC waters for fishing vessels of all Member States. According to this decision, the management of EC fisheries should be common as the use of fishery resources was common. A structural policy, to improve and adapt structures of the fisheries sector, and a market policy were first adopted in 1970. They refered largely to the agricultural background. This was the start of the long building of the CFP which was not completed before 1983, when the EC agreed on a system for the conservation and management of fishery resources by adopling the Regulation (EEC) $n^{\circ} 170 / 83$. From 1983 to 1992, this basic text supported the socalled conservation policy. As pointed out by the Commission of the European Communities in 1991 (CEC, 1991), this policy, which was essentially based on Total Allowable Catches (TACs), to be agreed each year in principle for each stock or group of stocks, and has driven largely the whole CFP. The proportion of landings subject to TACs in total EC landings confirms the importance of the TACs in the CFP. According to official statistics reported to the International Council for the Exploration of the Sea (ICES), its order of magnitude is $60-70 \%$ for the whole landings and $65.75 \%$ when only landings of fintish are considered ").

Often described as a failure, in view of the number of depleted stocks in North European waters. the conservation policy was revised in 1992. The Regulation (EEC) $n^{\circ} 3760 / 92$, which has replaced the Regulation (EEC) $n^{\circ} 170 / 83$ since the end of 1992 , put some stress on other management instruments than TAC, e.g. licences, and on the possibility of using TACs by fishery or over several years. Nevertheless, the annual TACs by stock are still in force and yet a major component of the CFP. An evaluation of their use seems then interesting to investigate, by an examination of facts, if the TAC system implemented in EC waters was really a failure and what could be learnt from mistakes of the past.

\section{MATERIAL AND METHODS}

The Regulation $n^{\circ} 170 / 83$ provides that the objectives of the conservation policy are "the

(1) Estimates based on years 1984 and 1988, complcte official statistics being not available for subsequent years at the time of this study. conservation of the biological resources of the sea and their balanced exploitation on a lasting basis". As measures "shall be formulated in the light of the available scientific advice", a Scientific and Technical Committec for Fisheries (STCF) was established for that purpose. In practice, STCF endorses the advice provides by the Advisory Committee on Fisheries Management (ACFM) of ICES, an institution which has developed an experience in stock assessments for many years within its Working Groups. Therefore, the annual reports of ACFM were the source of information which was used to examine how the achievement of the EC objectives has bcen evaluated in the 1983-1992 decade.

The annual $\triangle$ CFM recommendations, in term of fishing mortality, give a mean to evaluate to what extent the exploitation has been estimated to be "balanced" from 1983 to 1992. Two choices were made to get an homogeneous data set. First, the upper fishing mortality limit was chosen when the recommendations were open on a range of TACs, according to the effect of such recommendations. Indeed, in nearly nine cases out of ten, agreed TACs were above or close to the upper limits. Secondly, when a $30 \%$ decrease of fishing effort was recommended instead of a TAC, as in 1990-92 for some demersal slocks, a $20 \%$ decrease of fishing morality was chosen in this this case, given the closeness of the corresponding TACs to the agreed TACs.

This evaluation is possible only for stocks on which recommendations are documented, i.e. when analytical assessments were carricd out. Otherwise, the stocks are not considered to be known enough to provide a recommendation other than a precautionary TAC based on recent catches. However, analytical assessments are carried out for stocks which contribute most to landings subject to TACs. Their landings amount to half the total landings subject to TACs in 1984 and 1988, and up to nearly three quarters in 1992. For the demersal species in the North Sea and the pelagic species in all areas, this proportion amounts even to nearly three quarters in 1984 and 1988, and to about $90 \%$ in 1992. The evaluation of the achievement of the EC objectives, if it is not exhaustive, is consequently based upon a group of stocks which contribute to the Iandings subject to TACs in a proportion which gives some support to its representiveness.

The next step in the evaluation is the examination of the means used to achieve the objectives. The study is focused on the enforcement of TACs and on the consideration given to scientific advice, as TACs are the major - if not the only - tool of the policy, and as scientific advice must be considered, according to the agreed regulation.

Three years were selected to assess the implementation of the TAC system supported by the 1983 regulation. Because of the late approval of the TACs for 1983, the first year is 1984. The last one is 1992 
and 1988 was selected as an intermediate point. As a preliminary remark, it must be underlined that TACs refer practically to landings and not to catches, given that controls are on landings and that discards are ignored in catches as officially reported. Reports of ICES working groups on stock assessments provided landings for most of the TACs $(98 \%)$. The remainder was completed with official figures when available (years 1984 and 1988).
A particular difficulty was how to deal with the corrections to official figures, which are given as a total of unallocated catches in ICES working groups reports. They represent a proportion of the total catches ranging from 7 to $19 \%$, depending on the year, and must to be shared between EC members and nonmembers. Due to the lack of relevant information, the choice has been made of allocating them in proportion to official catches. This leads to assign a

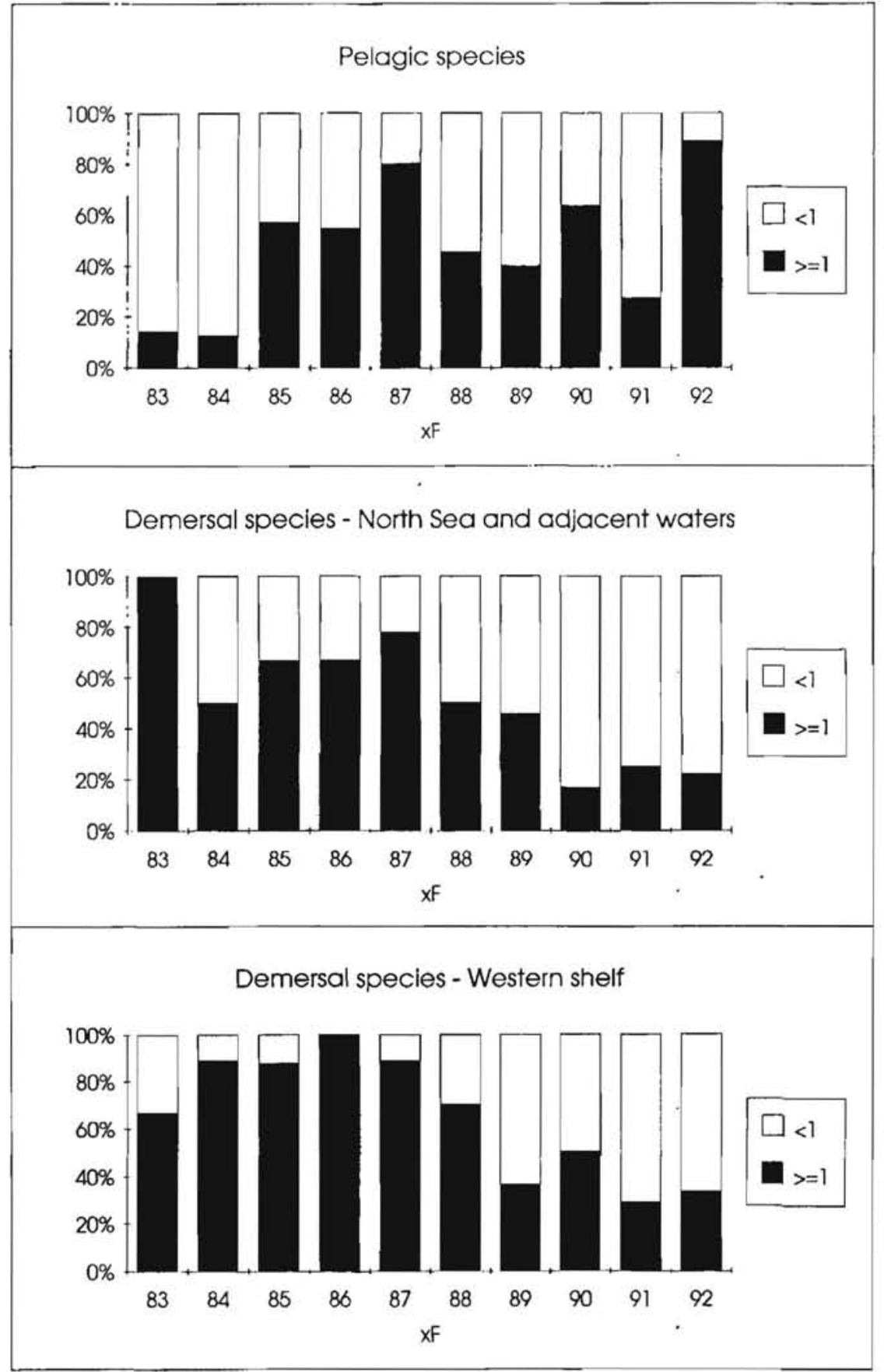

Figure 1. - Distribution of recommended fishing mortality multipliers (xF). 
large proportion of unallocated catches to EC member states. Indeed, the resulting non-EC share is less than one per cent of the estimated total EC landings (subject to TACs) for the demersal and industrial species. This proportion is higher in the case of the pclagic species. It ranges between 3 and $9 \%$, compared to 7 to $21 \%$ for EC member states, due to the importance of unallocated catches for these species. Finally the chances of underestimating EC landings are limited or, if there are some possibilities for pelagic species, it is of minor importance in the conclusions, given the level of enforcement of TACs for these species as shown hereafter.

EC landings, estimated from data which were validated and possibly corrected by experts for stock assessments, have thus an accuracy which appears largely sulficient for an overall check of TACs enforcement over several years. Three groups of species (pelagic, industrial and demersal) and three areas for demersal species were considered.

To see to what extent the TACs setting gives consideration to scientific advice, the condition to have at least four consecutive years of TACs based upon analytical assessments was laid down to study year to year changes. 30 stocks were thus selected, they account for more than $95 \%$ of EC landings subject to TACs based upon analytical assessments in 1984 and 1988 and for almost three quarters in 1992. When a range of TACs or a decrease of fishing effort were recommended, TACs were defined with the rules used previously for the recommendations of fishing mortality. The study is based on the examination of two indices: the positive difference between agreed TACs and recommended TACs based upon analytical assessments, and a stability index which allows to compare year to year variations of agreed TACs to those of recommended TACs (formula of both indices in annex).

\section{RESULTS}

\section{Achievement of the EC objectives from 1983 to 1992}

The number of recommendations of reductions in fishing mortality has largely increased throughout the decade 1983-1992 for the demersal species, whatever the area (fig. 1). There is no doubt from this trend that the exploitation was not considered to be "balanced" for these resources, the state of which has generally worsened since 1983. On the contrary, the trend in recommendations for the pelagic species shows that ACFM has become less concerned about the exploitation rate of these resources owing to the recovery of these stocks during the last decade.

\section{Enforcement of TACs}

Over the years 1984, 1988 and 1992, the total of EC TACs ranged from 3.1 to 3.5 million tonnes, whereas the EC landings were from 2.6 to 2.9 million tonnes (table I). By groups of species, and by areas for demersal species, landings were also lower than the TACs, except for the pelagic species in 1984 and 1988 and for the demersal species on the Southern Shelf in 1984. This result underlines that a lot of TACs are not restrictive, but the enforcement of TACs is far from being universally effective as shown by the distributions of differences between each TAC and the corresponding landing ( $f g . .3$ ).

The landings of pelagic species are frequently larger than the TACs and no limiting effect of the TACs is noticeable. The generally unrestrictive levels of TACs for industrial species is clearly shown. On the other hand, for demersal species there are signs of adjustement between landings and TACs as the distributions of differences between the two are rather symmetrical on either side of the class of differences ranging from minus $20 \%$ to 0 .

From available landings statistics, it must be admitted that TACS are only slightly exceeded, except for pelagic species. However, when available estimates of discards are taken into account, this satisfactory conclusion on TACs implementation is significantly altered, if one considers that TACs should aim at limiting catch. The possibility of achieving this is questionable for several demersal species, given that discards are estimated to amount to about $60 \%$ of North Sca haddock landings, $30-50 \%$ of West Scotland haddock landings, $20.60 \%$ of landings of whiting from the North Sea or from the Northern Shclf, 10-20\% of landings of megrim and sole from the Southern Shelf and $3 \%$ of northern hake landings.

\section{TACs setting and scientific advice}

Whon evaluating how the scientific recommendations are used, the first problem is the discrepancy between stock areas and TAC areas. The scientific advice is given for a stock, elementary unit of observation for the fisheries biologists - i.e. independent and homogeneous population of one species with respect to the main biological parameters which are mortality, growth and recruitement - but stocks spread over areas which are not always the elementary management unit for setting TACs.

About one fifth of the number of TACs concerns stocks on which few studies are available and the boundaries of their distributions are not clear. About one fifth of the TAC areas are smaller than the stock areas, and another fifth includes several stocks or concerns several species. Finally, considering the stocks of which the areas are known, and defining that TAC areas (one or several) correspond to the stock areas when they account for more than $95 \%$ of the eatches, only half of the EC TAC areas are 
Table 1. - European Community TACs and cotresponding landings and discards ( 000 ) in North-East Atantic and adjacent waters. (1) North Sea = ICES Sub-area IV; Norv. (Norvegian) Sea = ICES Division II a: a., (adjacent waters) = ICES Division VII $\&$ II b, ICES Sub-areas I \& III. Noth. (Northern) Shelf $=$ ICES Sub-area VI and Division VII a; East Greenland $=$ ICES Suh-area XIV; a.w. (adjacent waters) $=1$ CES Sub-areas $V \&$ XII. Southern Shelf = ICES Sub-areas VII (Divisions VII a and VId excepted), VII, IX, X (ICES Subareas and Divisions are shown on a map in fig. 2). N.B.: TAC of hake in Sub-areas V b, VI. VII, XII and XIV, TAC of megrim and monk in Sub-areas V b. VI, VII and VIII in 1984 are allocatcd to Southern Shelf. (2) Proportion of EC TACS covered by catch data: $100 \%$ in 1984 and 1988 , $98 \%$ in 1992. Sources of data: ICES Working Group Reports (all data except $2 \%$ of landings from ICES Fisheries Statistics in 1984 and 1988). (3) Sum of absolute values of estimated EC unallocated landings (estimated as for the discards, see below) to account for negative corrections. (4) Pro rata estimates in proportion of EC lundings in total landings when discards are availabie in ICES WG reports. (5) Including corrections for unallocated landings, (6) EC Quotas in non-EC areas included. (7) Landings as officially reported to ICES. (8) Proliminary. (9) Official statistics not fully conpleted in 1992.

\begin{tabular}{|c|c|c|c|c|c|c|c|}
\hline Year & Species & $\begin{array}{c}\text { EC TAC areas (1) } \\
\text { (EC = European } \\
\text { Community })\end{array}$ & \multicolumn{3}{|c|}{ Estimaled EC Catches (2) } & $\begin{array}{l}\text { European } \\
\text { Community } \\
\text { TACs (6) }\end{array}$ & $\begin{array}{c}\text { Official } \\
\text { EC Lambings: } \\
\text { (1) }\end{array}$ \\
\hline \multirow{4}{*}{1984} & Industrial & All & 0.0 & 0.0 & 494.5 & 913.5 & 513.4 \\
\hline & Demersal & North Sea, Norv. Sea \& a.w. & 75.4 & 110.9 & 951.6 & 991.4 & 894.3 \\
\hline & & North. Self, East Greenland a.w. & 5.1 & 20.1 & 147.8 & 229.5 & 146.2 \\
\hline & Total & All & 170.1 & 139.4 & 2792.7 & 3169.1 & 2610.3 \\
\hline \multirow[t]{4}{*}{1988} & Pelagic & $\mathrm{NI}$ & 301.0 & 17.6 & 1425.2 & 1280.8 & 1194.0 \\
\hline & Industrial & All & 0.0 & 0.0 & 293.6 & 758.0 & 402.7 \\
\hline & Demersal & North Sea, Norv, Sea \& aw. & 84.3 & 88.6 & 795.5 & 911.5 & 745.8 \\
\hline & & North. Selt, East Grcenland \& a.w. & 8.8 & 11.1 & 162.4 & 191.6 & 168.6 \\
\hline \multirow[t]{6}{*}{ (8) } & Industrial & All & 0.0 & 0.0 & 386.3 & 630.1 & (9) \\
\hline & Demersal & North Sea, Nory, Sta \& a.w. & 61.5 & 73.8 & 535.4 & 591.4 & (9) \\
\hline & & North. Self, East Greenland $\&$ aw. & 0.0 & 9.8 & 86.1 & 122.7 & (9) \\
\hline & & Southem shelf & 0.8 & 5.1 & 176.5 & 299.8 & (9) \\
\hline & & Total demersal & 62.4 & 88.7 & 798.0 & 1013.0 & (9) \\
\hline & Total & All & 305.7 & 120.6 & 2629.2 & 3099.0 & (9) \\
\hline
\end{tabular}

consistent with the need for a TAC management by stock. However that is the case for most of the major stocks assessed analytically, and therefore the dissimilarities between TAC and stock areas are of minor importance when evaluating the attention paid to scientific recommendations for these stocks.

The latter was examined with reference to the distribution of the positive differences between agreed and recommended TACs. This shows that consideration is given to scientific advice since: for most of the stocks, the positive differences are less than $15 \%$ (fg. 4). The second major finding, which emerges from the study, is that the year to year changes of agreed TACs are frequently lower than the ones of recommended TACs. The stability index is more than $25 \%$ lower for agreed TACs than for recommended TACs in two thirds of the cases ( fig. 5). The reduction can be noted when recommended TACs increase as well as when they decrease (fig. 6) and its magnitude is often important. On the contrary, the amplifications of variations of recommended $\mathrm{TACs}$ are often small. They occur mainly when recommended TACs decrease and represent compensatory phenomena due to previous decreases of agreed TACs less large than the ones of recommended TACs.

This study shows that the TAC decision process gives preference to stability but is also guided by the scientific recommendations, even if delays, reduction and amplifications of recommended changes may sometimes suggest the opposite. Going further in the analysis on the same group of TACs based upon analytical assessments, a comparison between landings and agreed TACs shows that, as described previously for all the EC TACs, the landings seldom exceed TACs in large proportions except in the case of the pelagic stocks. In about $75 \%$ of the cases, the positive differences between landings and agreed TACs (based upon analytical assessments) are less than $10 \%$ and the positive differences berween landings and recommended TACs are less than $20 \%$.

\section{DISCUSSION}

The TAC system implemented in the European waters depends on stock assessments that demand a 
G. Biais

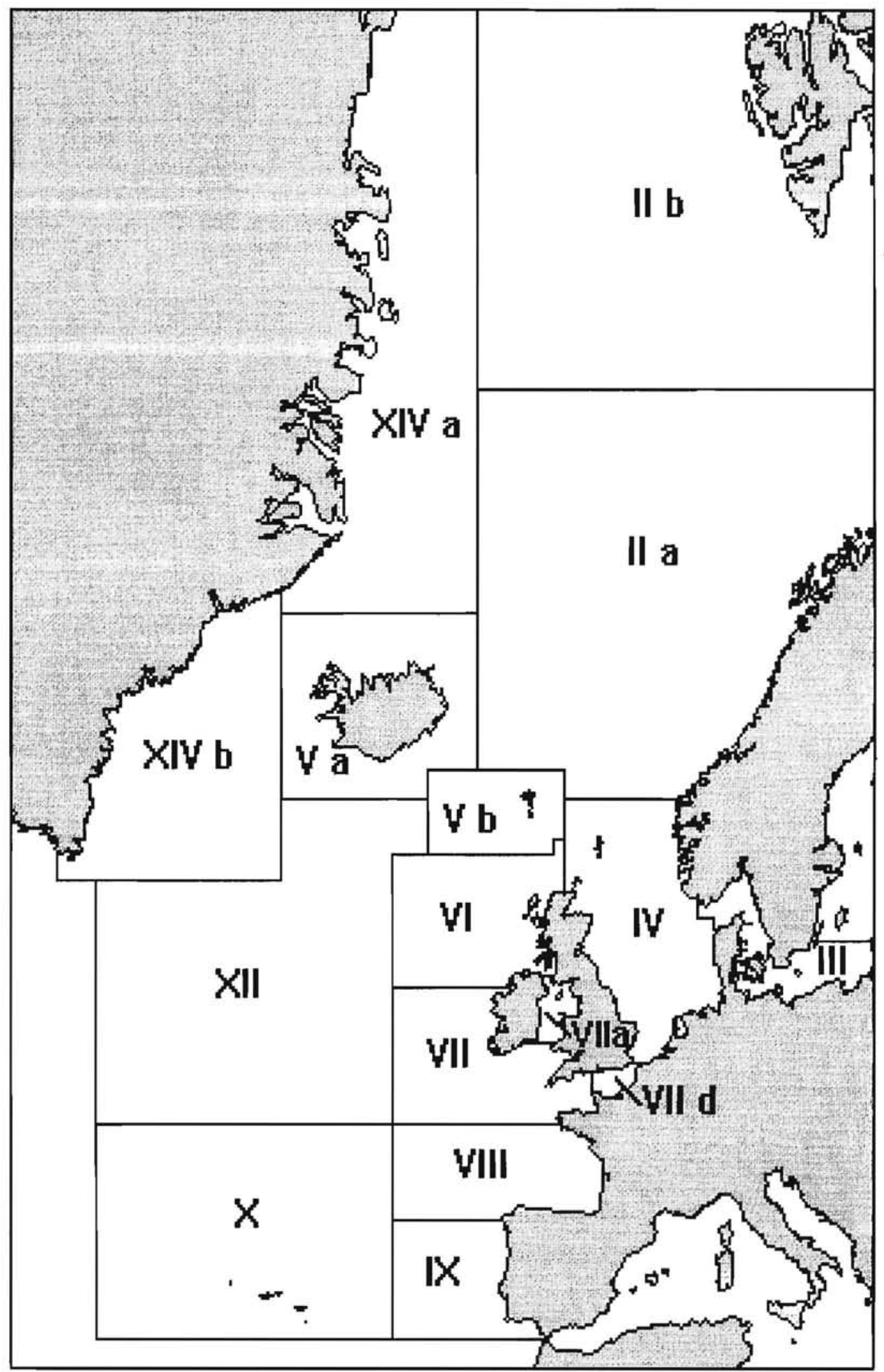

Figure 2. - International council for the Exploration of the Sea (ICES/CIEM) subareas and divisions. 

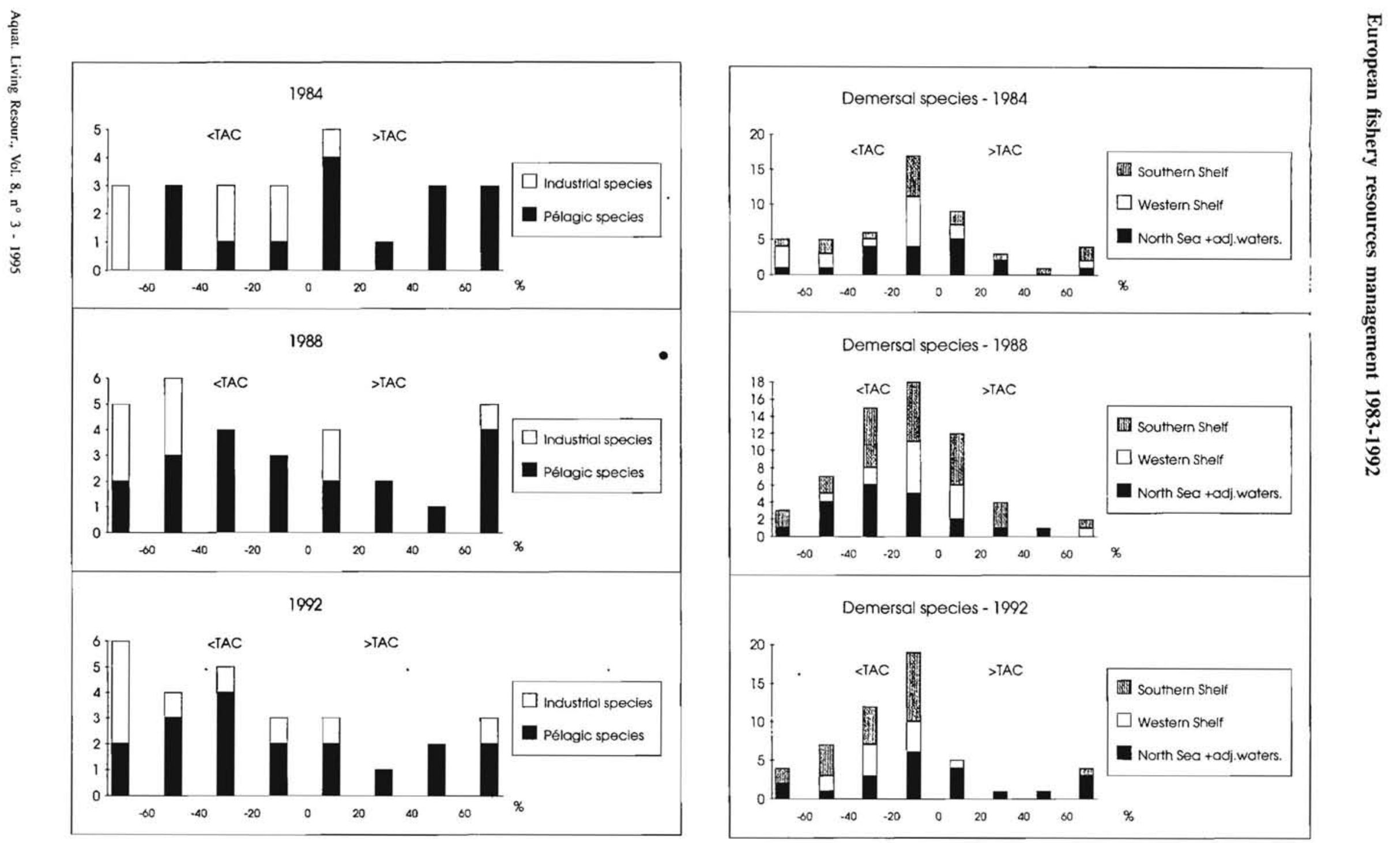

Figure 3. - Distribution of differences between estimates of EC landings and EC TACs relative to landing (in $\%$ ): (landing - TAC)/landing. 
large amount of data and are very time consuming for fisheries biologists. This paper presents some encouraging results as to the importance given to stock assessments, considering the attention paid to scientific recommendations, and to the increasing proportion of landings subject to TACs based upon analytical stock assessments. Unfortunately, these satisfactory results are offset by the deterioration of the state of a large number of European demersal stocks during the decade 1983-92. The paradox of pelagic species, of which landings greatly exceed TACs when the state of these stocks is not a matter of concern, emphasizes a feeling of limited impact of the management of fishery resources in the EC.

This lack of effect is more sharply felt for roundfish stocks in the North Sea and West of Scotland. Despite the fact that agreed TACs and landings were in line with recommended TACs, the fishing mortality has not been reduced as it should have been. Discards, misreportings and under-reportings of catches are thought to be responsible for this failure of TAC implementations (ICES, 1991; ICES, 1992). They undoubtedly contribute to limit the quality of the eatch forecasts, regarding the predicted effects on fishing mortality.

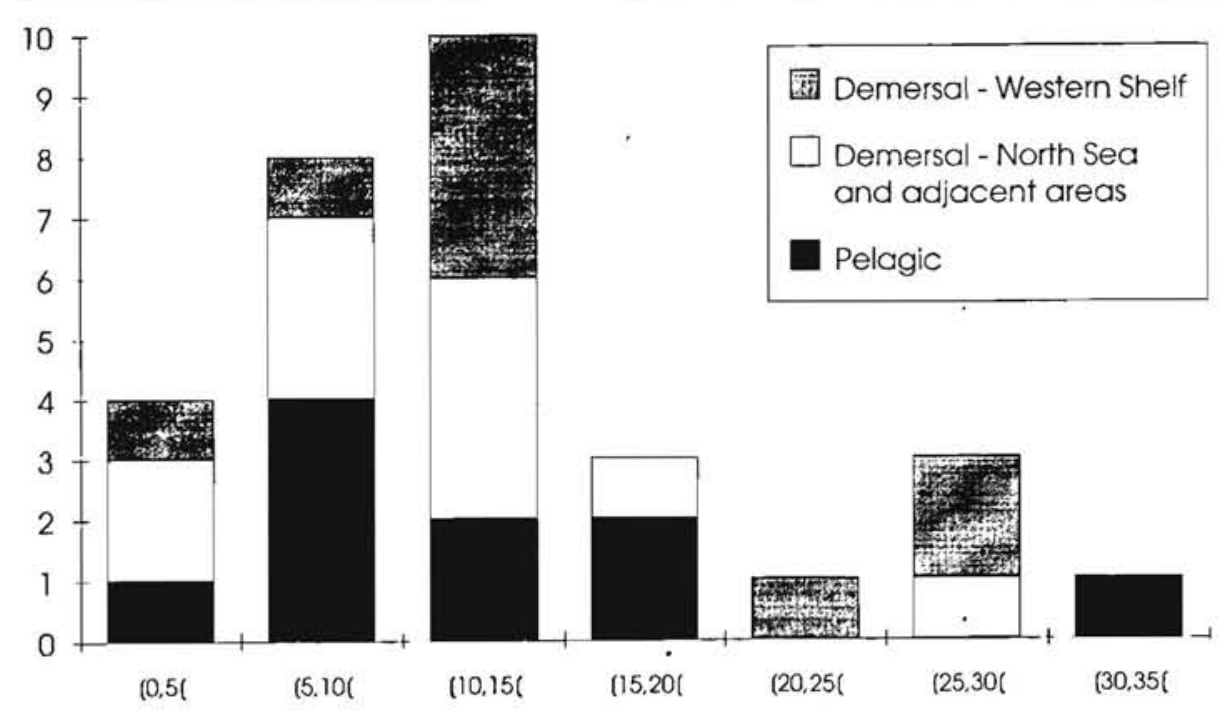

Figure 4. - Distribution (in number) of positive differences between agreed TACs and recommended TACs (in $\%$ of agreed RACs).

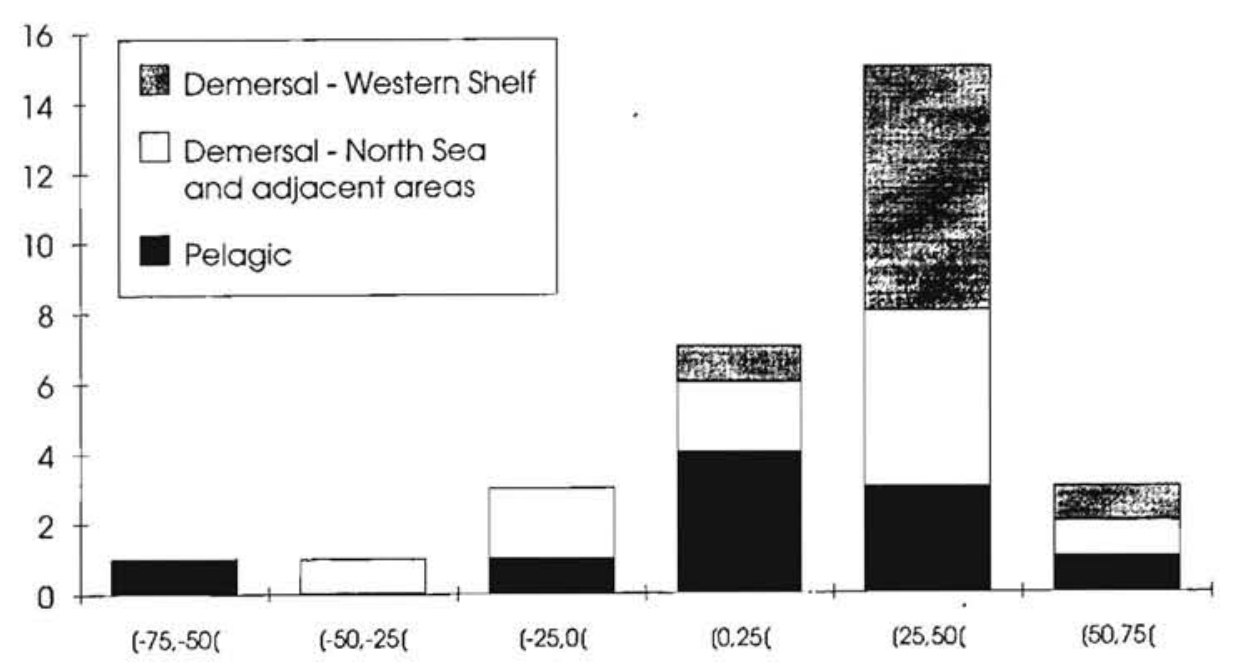

Figure 5. - Distributions (in number) of differences between Stability Indices of recommended TACs and of agreed TACs (in $\%$ of Stability Indiccs of recommended TACs). 


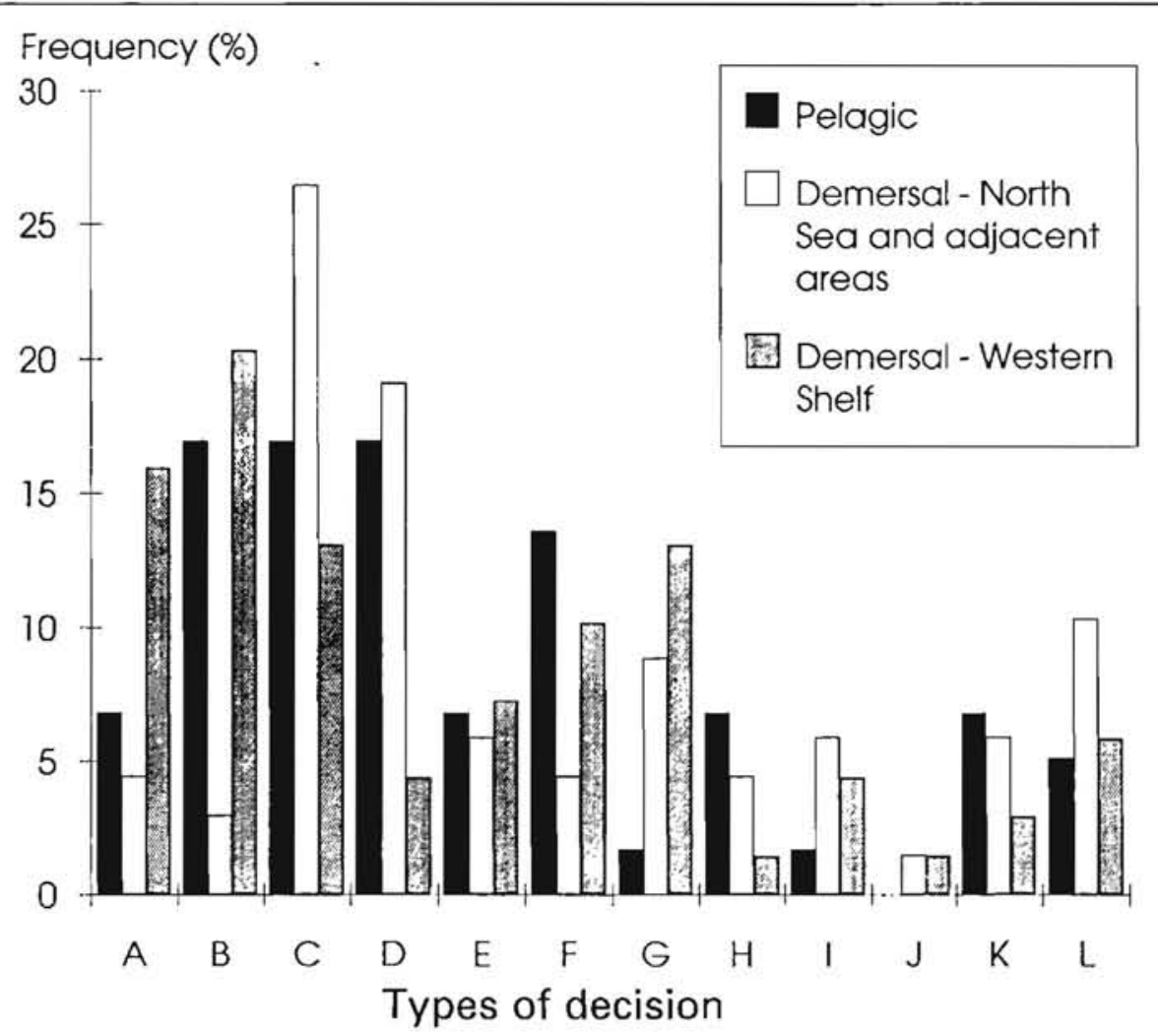

\begin{tabular}{|l|l|l|}
\hline & recommanded TAC & agreed TAC \\
\hline $\mathrm{A}$ & decreases & decreases less largely (1) \\
$\mathrm{B}$ & increases & increases less largely (1) \\
$\mathrm{C}$ & decreases & decreases less \\
$\mathrm{D}$ & increases & increases less \\
$\mathrm{E}$ & decreases & same change \\
$\mathrm{F}$ & increases or constant & same (no) change \\
$\mathrm{G}$ & decreases & decreases more \\
$\mathrm{H}$ & increases & increases more \\
$\mathrm{I}$ & decreases or constant & decreases more largely (2) \\
$\mathrm{J}$ & increases or constant & increases more largely (2) \\
$\mathrm{K}$ & decreases & increases \\
$\mathrm{L}$ & increases & decreases \\
\hline
\end{tabular}

(1) ratio of relative variations $<.1$

(2) ratio of relative variations $>10$

Figure 6. - TAC decisions relatively to recomended TACs.

Differences between estimated catches (including discards when estimated) and recommended catches (TAC and predicted discards, if any) show no close relationship with differences between mean fishing mortality multipliers in the latest available virtual population analysis and recommended mean fishing mortality multipliers, between the year of forecast and the TAC year ( fig. 7). It is worth noting that the problem extends to a lot of stocks, and not only to roundfish stocks, but the points under the $x$ axis for positive differences of fishing mortality multipliers show that the lack of accuracy of the catch forecast has often resulted in a higher fishing mortality than predicted for these stocks. 


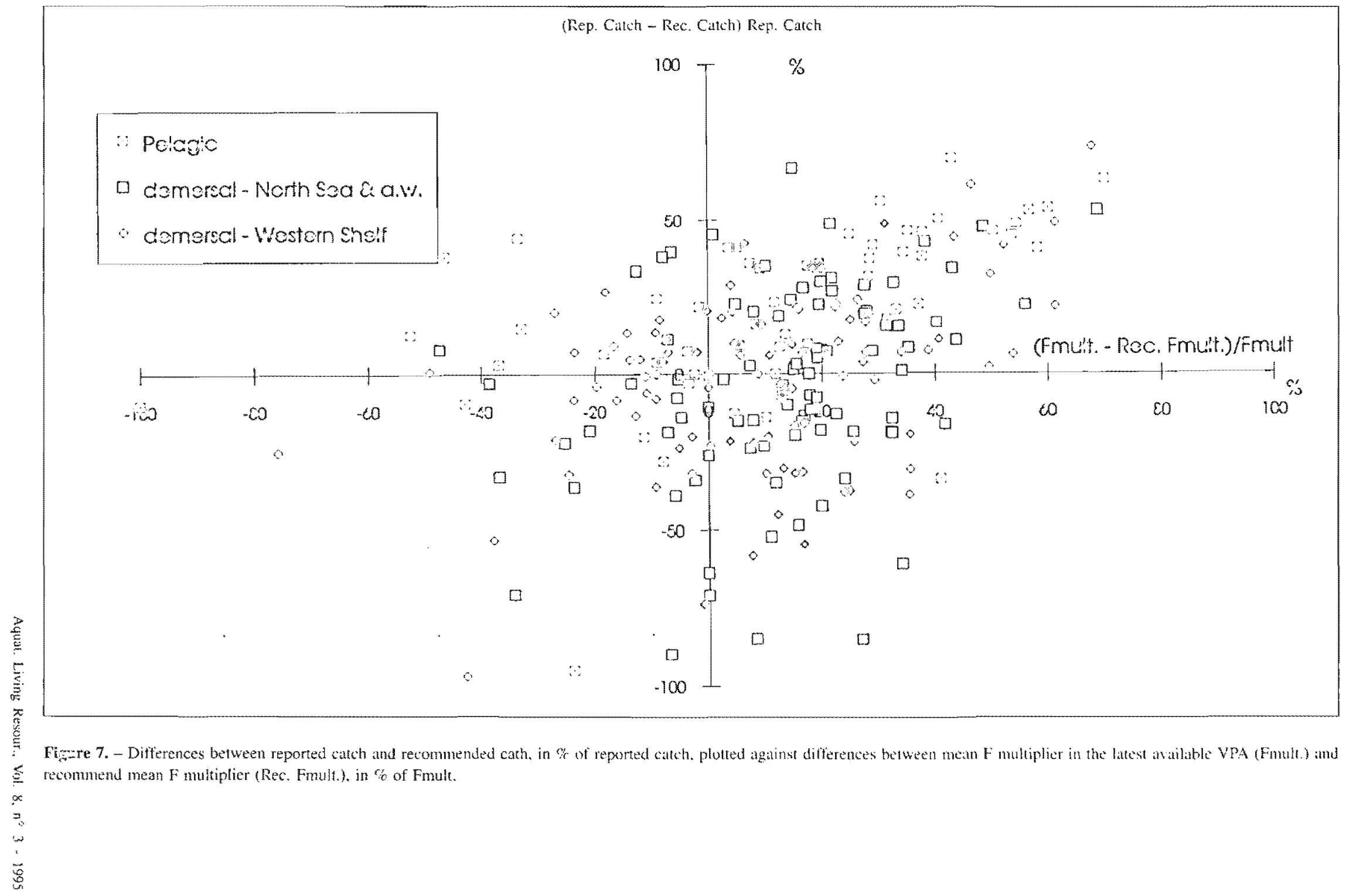


When the problem arises several times, the cumulative effect may be disastrous and leads to depleted stocks, even if TACs and landings are fairly close to scientific recommendations, as observed for the demersal stocks in EC waters during the 1983-1992 decade.

\section{CONCLUSION}

The low accuracy of catch forecasts was noticed some years ago (Brander, 1987) and there have been some attemps in recent years to estimate the variability of stock assessments within ICES Working Groups. However, in the TAC decision process, the problem is either ignored or emphasized when it undermines the recommended TAC options. The uncertainties in stock assessments, and therefore in stock managements, are not yet well recognized. The recommended changes in management practices in the European waters, such as the direct control of fishing effort, may help to improve the control of fishing mortality but the need to pay attention to uncertainties will certainly remain important. Expericnce shows that fishing effort restrictions are far from being a precise tool to control fishing mortality.

Setting TACs annually as in the EC is based on the possibility of tracking the year to year changes of biomass by using the most up to date catch predictions. This management schedule is supposed to allow to restore gradually the state of stocks, when necessary, or to take advantage of increases in biomass. The study of the TAC implementation in the EC over a decade shows that this pursuit of accurate management may be ruined by the uncertainties in stock assessments which play a part in the failure of TACs to avoid stock deteriorations. Even if the accuracy of catch forecasts was significantly increased by a better monitoring of catches, and more particularly of discards, "it is only reasonable and prudent to express the results of stock assessments in probabilistic terms" (Pearse and Walters, 1992). This means that there is some room for explicit account of risks in the decision making process. Assessment of different types of risks and participation of actors of the fishing sector in risks management are then important matters which cannot be avoided if one wants to improve the legitimacy of fisheries management and therefore its efficiency.
It seems necessary to address these challenges before advocating other instruments than TAC.

\section{REFERENCES}

Brander K. 1987. How well do working groups predict catches? J. Cons, int. Explor. Mer, 43, 245-252.

CEC 1991. Report 1991 from the Commission to the Council and the European Parliament on the Common Fisheries Policy, Commission of the European Communities, Brussels, SEC (91) 2288 final, 75 p.

ICES 1991. Report of the ICES Advisory Committee on Fishery Management, 1990. ICES Coop. Res. Rep. 173, $386 \mathrm{p}$.

ICES 1992. Report of the ICES Advisory Committee on Fishery Management, 1991. ICES Coop. Res. Rep. 179, part 1, $368 \mathrm{p}$.

Pearse P. H., C. J. Walters, 1992. Harvesting regulation under quota management systems for ocean fisheries. Mar. Policy 16, 167-182.

\section{ANNEX}

Positive difference:

Given $n$ pair of variables $\mathrm{X}_{2}$ and $\mathrm{Y}_{2}$, let $\mathrm{D}_{i}=\mathrm{X}_{i}-\mathrm{Y}_{i}$.

The positive difference is:

$$
100 \cdot \frac{\Sigma E_{i}}{\Sigma X_{i}}
$$

where $\mathrm{E} i=\mathrm{D} i$ if $D i \geq 0$ and $\mathrm{E} i=0$ if $\mathrm{D} i<0$.

Stability index:

Given the variable $\mathrm{X}_{i, j}$, with $m$ sequences
of $n_{j}$ values when ${ }_{i}$ varies from 1 to $n_{j}$ and $j$ varies from 1 to $m$ : $\mathrm{X}_{1,1}, \ldots, \mathrm{X}_{n_{1}, 1}, \ldots, \mathrm{X}_{1, j}, \ldots, \mathrm{X}_{n_{2}, 1}, \ldots, \mathrm{X}_{1, m}, \ldots$ $X_{n, m}, m$

The stability index is:

$$
100 \cdot \frac{\sqrt{\sum_{j}^{m} \sum_{i}^{n_{j}-1}\left(X_{i+1, j}-X_{i, j}\right)^{2}}}{\sum_{j}^{m}\left(n_{j}-1\right)^{n_{i}} \sum_{i}^{n_{j}} \frac{X_{i, j}}{n_{j}}}
$$

